\title{
Revista Polímeros: Ciência e Tecnologia
}

A revista Polímeros: Ciência e Tecnologia completará neste ano de 2011, 20 anos de existência. Durante todos esses anos, a revista criada pela Associação Brasileira de Polímeros, sempre buscou por contínuas melhorias, tendo como objetivo, primar pela qualidade e o incentivo aos autores em divulgar suas pesquisas.

A Revista Polímeros: Ciência e Tecnologia é composta por um corpo editorial que auxilia outros cientistas a apresentarem seus trabalhos da melhor maneira e de forma bastante significativa.

Desde sua criação, em 1988, quando foi lançada a revista, até então intitulada como Boletim, ela passou por etapas indispensáveis.

O primeiro boletim era composto de 33 páginas em papel carta, editado pelos Professores Silvio e Sati Manrich, com a colaboração de Carlos Alberto Flávio Corrêa, hoje professor da Universidade São Francisco e sócio da ABPol, e possuía como ênfase promover uma discussão ocorrida na fundação da Associação Brasileira de Polímeros.

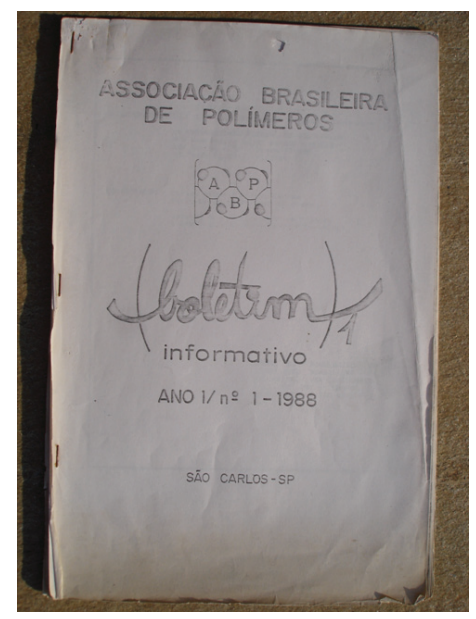

Figura 1. Primeiro boletim da ABPol publicado em dezembro de 1988.

\section{1 - Lançada a Revista "Polímeros: Ciência e Tecnologia"}

Em junho de 1991 foi lançada a Revista Polímeros: Ciência e Tecnologia, criada devido à necessidade de incentivo a publicações na área e também de um periódico brasileiro especialmente voltado para a área de Polímeros.

O primeiro número da revista foi distribuído no primeiro Congresso Brasileiro de Polímeros ( $\left.1^{\circ} \mathrm{CBPol}\right)$. A capa trazia o logotipo do congresso, realizado no Anhembi em São Paulo, e teve como tiragem cerca de 3.000 exemplares.
O primeiro comitê editorial da revista era composto por Francisco J. X. de Carvalho, José Alexandrino de Souza, Renato Ciminelli, Sebastião Canevarolo e Silvio Manrich.

Com o passar dos anos a revista teve reconhecimento, tanto nacional como internacional, permanecendo desta forma até os dias atuais. A primeira edição da revista continha 6 artigos científicos e atualmente cada uma das cinco edições anuais contém 14 artigos.

Até o presente a revista já publicou 727 trabalhos originais, os quais passaram por rigorosas avaliações de, pelo menos, dois árbitros, objetivando a qualidade dos trabalhos publicados.

A revista Polímeros: Ciência e Tecnologia, desde novembro de 1991, está plenamente consagrada junto à comunidade científica de polímeros do Brasil e, reconhecida em nível internacional através de sua indexação pelo Chemical Abstract, RAPRA Abstracts e atualmente na base de dados do ISI Web of Knowledge, Web of Science.

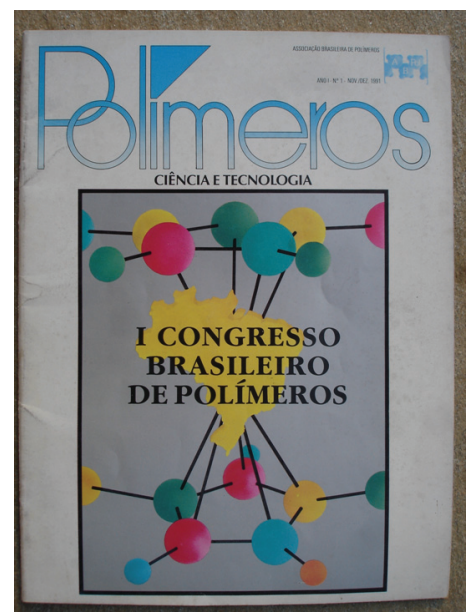

Figura 2. Revista "Polímeros: Ciência e Tecnologia" número um da Associação Brasileira de Polímeros lançada em novembro de 1991 (ANO 1 - No. 1 - NOV/DEZ 1991).

Desde 2006 a revista Polímeros: Ciência e Tecnologia pode ser acessada no site da revista, onde é encontrada sua versão eletrônica assim como os arquivos de todas as edições publicadas anteriormente e também no site do Scientific Electronic Library (Scielo- www.scielo.br).

Graças à dedicação e esforço de todos os envolvidos na revista Polímeros: Ciência e Tecnologia, assim como a qualidade dos trabalhos científicos publicados, a mesma é enviada para diversas entidades no exterior, tais como: Physical, Chemical \& Earth Sciences - Philadelphia, PA, USA; Chemical Abstract Service - Columbus, OH, 
USA; Librarian RAPRA Techonology Ltd. - United Kingdom; All-Russian Institute of Scientific and Technical Information; AIM Magazine, c/o Dipartimento di Chimica e Chimica Industriale - Italy, Polymer Processing Institute GITC - NJ, Inst. of Tech. University Heights - Newark, USA; The Polymer Society of Korea - Kangnam-ku, Seoul, Korea; Team Periodicals - TIB/UB - Hannover, Germany; The British Library - Boston Spa Wetherby, United Kingdom, Universidad Complutense de Madrid, Facultad de Químicas - Madrid, Spain, Universidad Autónoma del Estado de México - México.

O Comitê Editorial é composto atualmente por:

- Adhemar Collà Ruvolo Filho (UFSCar) - Editor chefe

- Bluma G. Soares (UFRJ/IMA)

- César Liberato Petzhold (UFRGS/IQ)

- Elisabete Frollini (USP/IQSC)

- Glaura Goulart Silva (UFMG/DQ)

- José Carlos C. S. Pinto (UFRJ/COPPE)

- Laura H. de Carvalho (UFCG/DEMa)

- Marco-Aurelio De Paoli (UNICAMP) - Presidente do Conselho Editorial

- Regina Célia R. Nunes (UFRJ/IMA)

A revista Polímeros alcançou a consolidação nacional e está alcançando cada vez mais o destaque internacional graças à dedicação de todos envolvidos.

Abaixo seguem alguns depoimentos de consultores e autores da Revista Polímeros: Ciência e Tecnologia

Professor Marcelo Rabello, Departamento de Engenharia de Materiais, Universidade Federal de Campina Grande: Uma revista informativa e científica com grande aceitação na comunidade acadêmica e industrial. Esse é o perfil da Polímeros. Muito mais do que isso: uma revista construída por nós, avaliada por nós e com vocação para a disseminação dos trabalhos desenvolvidos no Brasil. A cada ano, a cada edição, se observa claramente o aumento no nível de qualidade científica dos trabalhos ali publicados - decorrente também de um maior amadurecimento da comunidade de polímeros no Brasil. Certamente, a Polímeros se constitui em um grande marco na trajetória dos materiais poliméricos do país.

Paula C. Mazo, Departamento de Engenharia Química, Universidade de Antioquia: The study of polymers has a world importance, particularly in Latin America, where this topic has grown recently. This growth is reflected in a great series of works with high scientific, academic, and technologic impact published in this magazine. For this reason, I believe that the Polimeros is the only magazine in Latin America because through it is possible to find articles with high-quality scientific, and academic. Also, the themes disseminated here, allow a best interaction between Latin American researchers with the aim of strengthening the knowledge on polymer science.
Professora Bluma Guenther Soares, Centro de Tecnologia, Universidade Federal do Rio de Janeiro: $A$ Revista Polímeros: Ciência e Tecnologia tem se dedicado à divulgação do conhecimento científico e tecnológico que vem sendo desenvolvido pela Comunidade de Polímeros do Brasil, desde a sua criação em Novembro de 1991. Ela começou um pouco tímida, com a publicação de apenas seis artigos em seu primeiro fascículo. Entretanto, foi crescendo nesses últimos 20 anos e hoje pode ser considerada uma das mais importantes fontes de informação na área de Materiais Poliméricos do Brasil e da America Latina. Em todos esses anos de existência, a revista sempre manteve a sua periodicidade e a qualidade dos artigos científicos e atualmente consta da lista dos periódicos indexados no ISI Web of Knowledge e outras bases de pesquisa científica internacionais e nacionais. Esse sucesso deve ser creditado ao esforço contínuo dos editores e principalmente aos autores que acreditaram no seu crescimento, enviando artigos regularmente. Com a indexação, ela torna-se uma revista de visibilidade internacional e isso é fundamental para a divulgação de nossas pesquisas. As matérias dedicadas ao setor industrial vem confirmar o espírito da revista e da própria Associação Brasileira de Polímeros (ABPol) de aproximar sempre a experiência do setor industrial e da academia, visando o crescimento científico e tecnológico do País. É importante que esse espírito seja mantido para que juntos possamos aprender sempre e melhorar cada vez mais a nossa atuação como pesquisador, industrial, professor e outras atividade de igual importância para o País.

A revista Polímeros: Ciência e Tecnologia possui agora todos os requisitos para se tornar uma revista de importância internacional, sem perder de vista as necessidades Nacionais e Regionais. É importante que todos nós, envolvidos com a área de Materiais Poliméricos, continuemos prestigiando a NOSSA REVISTA não apenas enviando trabalhos de qualidade como também citando-a sempre que possível.

Professora Regina Célia Reis Nunes, Instituto de Macromoléculas Professora Eloisa Mano: Tendo o privilégio de participar desde o inicio da formação da Revista POLÍMEROS Ciência e Tecnologia é uma honra externar minha opinião sobre a importância deste periódico.

A POLÍMEROS ocupa atualmente posição de destaque no nosso País, na área de Ciência e Tecnologia e vem sendo lida não somente pelo segmento Acadêmico, mas também pelo segmento Industrial, na busca de inovação tecnológica, ambiental e de caracterização.

O fato de a Revista POLÍMEROS ser redigida em português tem facilitado a informação de uma forma geral, não significando que a publicação de artigos em inglês ou em espanhol não sejam importantes, mas devem ser a minoria, e sempre acompanhados de um resumo em português. Esta minha opinião é principalmente suportada por contatos que tenho recebido de industriais que, lendo os artigos na área que tenho publicado mostraram interesse em usar as informações em seus experimentos. 
Como pesquisadora brasileira parabenizo a Associação Brasileira de Polímeros pela publicação desta importante fonte de informações que é POLÍMEROS Ciência e Tecnologia desejando que cada vez mais se destaque como um veículo de comunicação cientifica e tecnológica no Brasil.

Professor Associado José Ricardo Tarpani, Departamento de Engenharia de Materiais Aeronáutica e Automobilística, Universidade de São Paulo: Reconheço na Revista Polímeros um excelente canal de comunicação e divulgação dos diversos resultados de nossas pesquisas realizadas na Área de Materiais Compósitos Estruturais Poliméricos.

Professora Mara Zeni Andrade, Departamento de Física e Química, Universidade de Caxias do Sul: Mesmo que nós tenhamos sobre nossas cabeças os valores de impacto ou classificações do Data Capes para cada área, com classificações bem diferentes, eu pesquisadora da área de polímeros e orientadora de IC até DR levo muito em consideração a experiência que o aluno tem que iniciar durante sua caminhada científica, escrevendo para Eventos e para as Revistas Nacionais e Internacionais sobre o seu trabalho.
A nossa "Revista Polímeros:Ciência e Tecnologia tem recebido apoio das agencias de fomento brasileiras, das empresas e da ABPol nas suas diversas atividades de eventos e colaborações.

Que bom que nossa revista está expandindo, agora com o DOI dos artigos e indexada nos maiores bancos internacionais.

Parabéns a atual diretoria da revista e colaboradores pareceristas.

Professora Glaura Goulart Silva, Departamento de Química, Universidade Federal de Minas Gerais: $A$ revista "Polímeros: Ciência e Tecnologia" é um elemento fundamental na evolução da comunidade científica da área de polímeros no estado de Minas Gerais. Os primeiros artigos com contribuições da UFMG apareceram nos anos de 1994-1995 e foram timidamente se ampliando nos anos seguintes. Em 2010 foram 10 trabalhos onde houve participação de grupos instalados em universidades das diversas regiões de Minas Gerais (UFOP, UFU, UNIFEI, UFV, UFSJ e UFMG). A consolidação da revista através de sua ampla indexação e impacto internacional é um marco de qualidade que desejamos continuar compartilhando.

\section{ABPol}

A ABPol, como entidade nacional representativa da área de polímeros, há mais de 20 anos vem prestando os mais relevantes serviços à comunidade, através da realização de Congressos de nível internacional, seminários técnico-mercadológicos, cursos de atualização profissional e edição da revista "Polímeros: Ciência e Tecnologia", dentre outras realizações.

A excelência dos profissionais do meio acadêmico e industrial que têm contribuído com a instituição foi, sem dúvida, fator determinante do elevado nível do trabalho oferecido pela $\mathrm{ABPol}$ a seus associados e à comunidade em geral.

Faça parte do quadro de Associados da ABPol e desfrute dos benefícios concedidos tais como:

- Descontos especiais em congressos, cursos, e eventos promovidos pela ABPol e ou apoiados por ela amplamente divulgado em nosso site e boletins informativos.

- Descontos na aquisição de livros mantidos em nosso acervo. Contamos hoje com 42 títulos disponíveis para venda no site da ABPol.

- Recebimento da revista Polímeros: Ciência e Tecnologia e de todo material de divulgação/informação. Publicação trimestral.

- Recebimento de carteirinha de identificação como associado da ABPol, que poderá ser apresentada na participação em eventos da ABPol e ou apoiados por ela.

Saiba mais, acessando o site: www.abpol.org.br

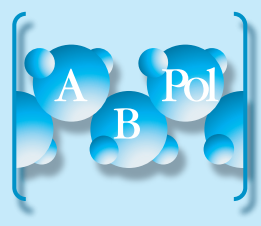

